\title{
Adult circumcision in the prevention of HIV/AIDS
}

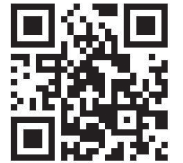

In this month's SAMJ, Millard et al. ${ }^{[1]}$ report the results of an innovative study comparing surgical circumcision to that using a Unicirc device plus tissue adhesive. This is a follow-up to their earlier study using a similar non-disposable device (Gomco) ${ }^{[2]}$ This study is timely because South Africa (SA) is not on target to meet its planned objective of circumcising $80 \%$ of men between the ages of 15 and 49 or 4.3 million by $2015^{[3]}$ and points the way toward a faster, easier method that may aid in voluntary medical male circumcision (VMMC) scale-up in areas of Africa with a high prevalence of HIV infection.

Three landmark randomised trials carried out in SA, Kenya, and Uganda were published in 2007..$^{[4-6]}$ The trials were all terminated early based on interim analyses that showed a significantly lower rate of newly-acquired HIV infection for the circumcised v. the uncircumcised men. These 3 studies later formed the basis of a Cochrane review, which confirmed the value of surgical circumcision with healing by primary intention as a method for preventing heterosexual HIV transmission. The combined results showed that VMMC reduced incident HIV infection rates by $60 \%$. Some people dismiss circumcision as a beneficial, preventive intervention, claiming that it encourages men to participate in unprotected sexual activity. The truth is that despite counselling and increased knowledge, the use of condoms remains sporadic among men. The differences between the control and circumcised groups would not have become apparent so quickly if the men had been using condoms as advised.

Based on this strong scientific evidence, VMMC is a priority intervention for the World Health Organization (WHO) and the President's Emergency Plan for AIDS Relief (PEPFAR). Circumcised men have a lower risk of acquiring HIV because, following circumcision, the epithelium of the glans penis becomes keratinised, and keratinised epithelium is largely resistant to the passage of HIVinfected T-cells.

Uncircumcised men, on the other hand, are at higher risk of HIV acquisition because the inner foreskin layer allows HIV-infected cells to form apical viral synapses with the dendrites of Langerhans cells present on the moist mucosal surface of the glans and inner part of the prepuce. ${ }^{[7]}$ Infected T-cells pass through the epithelial layer and attach to the dendrites of the Langerhans cells. The inner foreskin produces tumour necrosis factor, which stimulates the Langerhans cells via cytokines to produce an influx of $\mathrm{CD}^{+} \mathrm{T}$-cells. The Langerhans cells produce langerin, which binds HIV and helps the cells degrade it and transport the virus to local lymph nodes.

The WHO Global Health sector Strategy on HIV/AIDS for 2011 - 2015 has determined that scale-up of VMMC in Africa constitutes a high-impact, cost-effective intervention. They suggest scaling-up medical male circumcision to $80 \%$ coverage for 15 - to 49 -year-old males in 14 priority countries in sub-Saharan Africa by 2015. This will require 20.5 million circumcisions, and is expected to avert 3.4 million new HIV infections by 2025 . It will cost US $\$ 1.5$ billion, but save US $\$ 16.5$ billion of healthcare costs.

Each of the large African studies used an open surgical method of circumcision. Surgical circumcision has several disadvantages for scaling-up and reaching the above-mentioned ambitious targets: it requires a high level of surgical skill, is time-consuming (approximately $20 \mathrm{~min} /$ procedure) and is costly. Given these disadvantages of surgical circumcision, WHO has requested that new, more cost-effective techniques be developed to facilitate scaleup, which is already well behind schedule in most African countries with a high prevalence of HIV.

There are many different circumcision techniques. Development of clamps and rings for circumcision using modern materials began in the 1930s. One of the earlier prototypes came from the Goldstein Medical Company (Gomco). These older instruments allow the circumciser to remove almost the entire inner foreskin.

Recently, several disposable plastic devices have been developed. The new plastic ring devices are left in place for 1 week, and then removed in the clinic. The unpleasantness of wearing a plastic ring on the penis for a week, the smell of necrotic material, and the return visit for removal of the device negate many of the benefits. Because healing is by secondary intention, the delayed healing may facilitate new infections if sexual activity is not delayed for up to 6 weeks postoperatively.

The approach by Millard et al. ${ }^{[2]}$ using the Gomco device, while avoiding the problems of healing by secondary intention, provided other problems in keeping with the use of a nondisposable device. The single-use disposable Unicirc device ${ }^{[1]}$ also works by clamping the the foreskin, removing it and sealing the wound with cyanoacrylate tissue adhesive avoiding the use of sutures. This novel technique is much faster, simpler to learn, nearly bloodless and heals rapidly by first intention. Circumcision with the Unicirc device is $30-40 \%$ faster than using standard surgical methods. Adverse events were similar to those of the surgical control group. The intraoperative suture rate for the Unicirc was $17 \%$ initially due to the utilisation of inadequate tissue pressure. This rate should come down as the newer modifications of this device generate more tissue compressibility.

This device meets all the WHO criteria of a disposable, singleuse device to prevent cross-contamination, as occurred in the early phases of the HIV epidemic.

\section{Norman D Goldstuck}

Department of Obstetrics and Gynaecology, Tygerberg Hospital, Cape Town, South Africa

nahumzh@yahoo.com

\footnotetext{
1. Millard PS, Wilson HR, Goldstuck N, Anaso C. Rapid, minimally invasive adult voluntary male circumcision: A randomised trial of Unicirc, a novel disposable device. S Afr Med J 2013;104(1):52-57, [http://dx.doi.org/10.7196/SAM].7357]

2. Millard PS, Wilson HR, Veldkamp PJ, Sitoe N. Rapid, minimally invasive adult voluntary male circumcision: A randomised trial. S Afr Med J 2013;103(10):736-742. [http://dx.doi.org/10.7196/SAMJ.6856]

3. Malan M. Household survey: HIV prevalence increases. Mail and Guardian, 20 June 2013. http:// mg.co.za/article/2013-06-20-household-survey-hiv-prevalence-increases (accessed 2 July 2013).
.

mg.co.za/article/2013-06-20-household-survey-hiv-prevalence-increases (accessed 2 July 2013).
4. Advert B, Taljaard D, Legarde E, et al. Randomized, controlled intervention trial of male circumcision for reduction of HIV infection risk: The ANRS 1265 trials. Plos Medicine 2005;2(e218):112-122.
for [http://dx.doi.org 10.1371/journal.pmed.0020298]

[http://dx.doi.org 10.1371/journal.pmed.0020298] 5. Bailey RC, Moses S, Parker CB, et al. Male circumcision for HIV prevention in young men in Kisuma,
Kenya: A randomised controlled trial. Lancet 2007;369(9562):643-656. [http://dx.doi.org/10.1016/ S0140-6736(07)60312-2

6. Gray RM, Kigozi G, Serwadda D, et al. Male circumcision for HIV prevention in men in Rakai, Uganda: A randomised trial. Lancet 2007;369(9562):651-666. [http://dx.doi.org/10.1016/S0140-6736(07)60313-4] Morris BJ, Wamai RG. Biological basis for the protective effect conferred by male circumcision against HIV infection. Int J STD AIDS 2012;23(3):153-159. [http://dx.doi.org/10.1258/ijsa.2011.011228]
}

S Afr J Med 2014;104(1):17. DOI:10.7196/SAMJ.7216 